Genome Biology

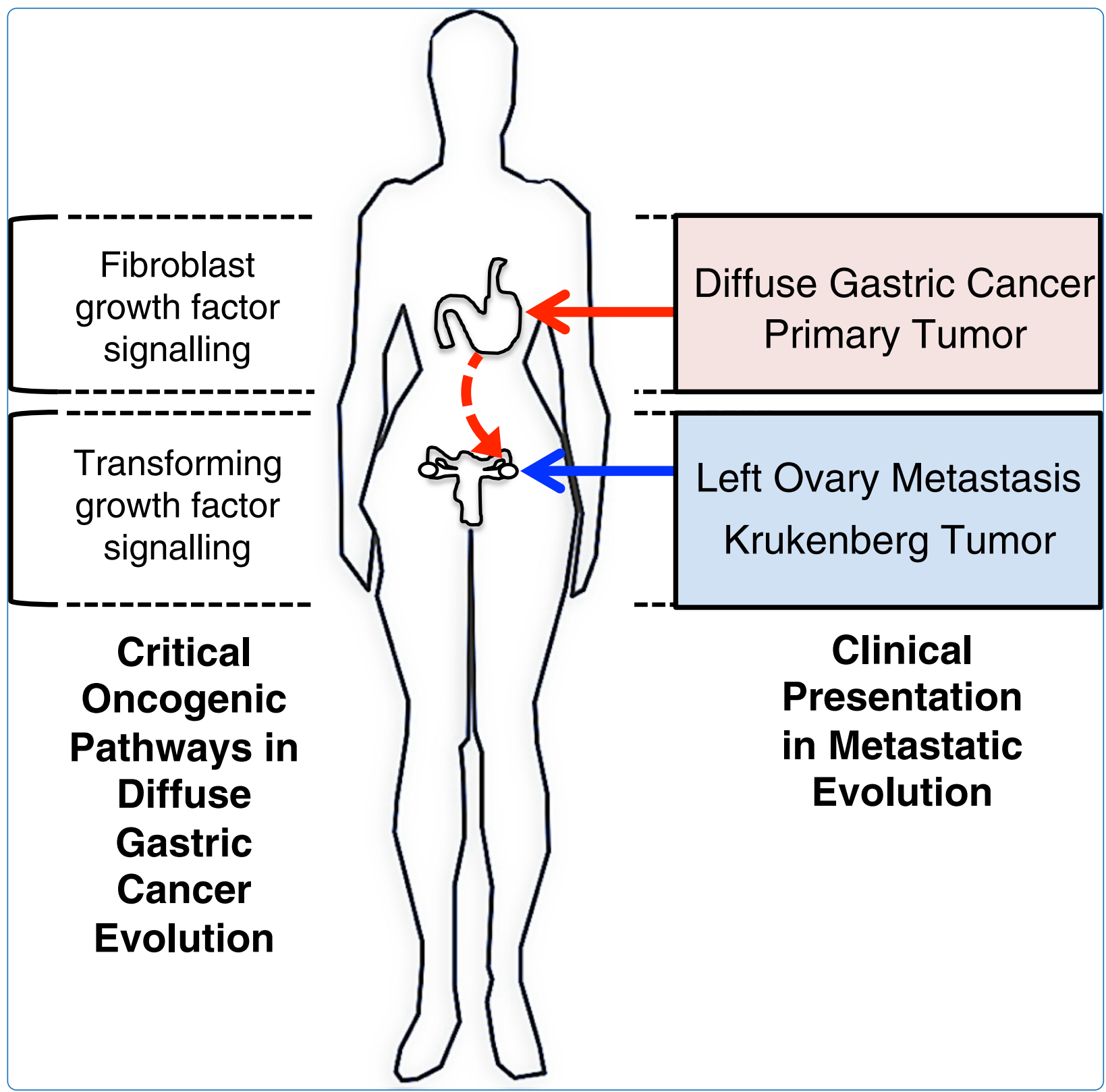

Metastatic tumor evolution and organoid modeling implicate TGFBR2 as a cancer driver in diffuse gastric cancer

Nadauld et al.

C Biomed Central 


\title{
Metastatic tumor evolution and organoid modeling implicate TGFBR2 as a cancer driver in diffuse gastric cancer
}

Lincoln D Nadauld ${ }^{1,2}$, Sarah Garcia ${ }^{2}$, Georges Natsoulis ${ }^{1}$, John M Bell², Laura Miotke ${ }^{1}$, Erik S Hopmans ${ }^{2}$, Hua Xu ${ }^{2}$, Reetesh K Pai ${ }^{3}$, Curt Palm ${ }^{2}$, John F Regan ${ }^{4}$, Hao Chen ${ }^{5}$, Patrick Flaherty ${ }^{2}$, Akifumi Ootani $^{6}$, Nancy R Zhang ${ }^{7}$, James M Ford ${ }^{1}$, Calvin J Kuo ${ }^{6^{*}}$ and Hanlee P Ji ${ }^{1,2^{*}}$

\begin{abstract}
Background: Gastric cancer is the second-leading cause of global cancer deaths, with metastatic disease representing the primary cause of mortality. To identify candidate drivers involved in oncogenesis and tumor evolution, we conduct an extensive genome sequencing analysis of metastatic progression in a diffuse gastric cancer. This involves a comparison between a primary tumor from a hereditary diffuse gastric cancer syndrome proband and its recurrence as an ovarian metastasis.

Results: Both the primary tumor and ovarian metastasis have common biallelic loss-of-function of both the CDH1 and TP53 tumor suppressors, indicating a common genetic origin. While the primary tumor exhibits amplification of the Fibroblast growth factor receptor 2 (FGFR2) gene, the metastasis notably lacks FGFR2 amplification but rather possesses unique biallelic alterations of Transforming growth factor-beta receptor 2 (TGFBR2), indicating the divergent in vivo evolution of a TGFBR2-mutant metastatic clonal population in this patient. As TGFBR2 mutations have not previously been functionally validated in gastric cancer, we modeled the metastatic potential of TGFBR2 loss in a murine three-dimensional primary gastric organoid culture. The Tgfbr2 shRNA knockdown within $\mathrm{Cdh}^{-1 /}$; $T p 53^{-\%}$ organoids generates invasion in vitro and robust metastatic tumorigenicity in vivo, confirming Tgfbr2 metastasis suppressor activity.

Conclusions: We document the metastatic differentiation and genetic heterogeneity of diffuse gastric cancer and reveal the potential metastatic role of TGFBR2 loss-of-function. In support of this study, we apply a murine primary organoid culture method capable of recapitulating in vivo metastatic gastric cancer. Overall, we describe an integrated approach to identify and functionally validate putative cancer drivers involved in metastasis.
\end{abstract}

\section{Background}

Worldwide, gastric adenocarcinoma is the fourth most common malignancy and the second leading cause of cancer deaths among men and women. Based on distinctive histopathologic features, gastric adenocarcinoma is categorized into diffuse and intestinal subtypes [1]. In terms of histopathology, diffuse gastric cancers are generally

\footnotetext{
* Correspondence: cjkuo@stanford.edu; genomics_ji@stanford.edu ${ }^{6}$ Division of Hematology, Department of Medicine, Stanford University School of Medicine, CCSR 1155, 269 Campus Drive, Stanford, CA 94305-5151, USA

'Division of Oncology, Department of Medicine, Stanford University School of Medicine, CCSR 1115, 269 Campus Drive, Stanford, CA 94305-5151, USA Full list of author information is available at the end of the article
}

undifferentiated, frequently have signet cell ring features and invasively infiltrate normal stomach tissue. In contrast, the intestinal subtype has epithelial features and forms discrete tumor masses similar to colon cancer. Diffuse gastric cancer has a higher incidence of metastatic disease and a generally worse prognosis compared to the intestinal subtype [2,3]. Currently, the genomic analyses of diffuse gastric cancer have involved a small number of samples including a recent study by the Cancer Genome Atlas Project (TCGA) and a whole genome sequencing survey of a set of diffuse gastric tumors [4]. However, there are few, if any, studies that detail the metastatic evolution of gastric cancer; metastatic tumors are typically absent from large-scale genomic cancer surveys such as 
TCGA. Overall, little is known about the oncogenic process and tumor evolution of metastatic gastric cancer despite its paramount clinical importance [5].

In hereditary diffuse gastric cancer (HDGC), germline mutations in $C D H 1$ (that is, E-cadherin) confer a 70\% lifetime risk of developing diffuse gastric cancer [6,7]. The CDH1 tumor suppressor gene encodes E-cadherin, a transmembrane glycoprotein that mediates calcium-dependent cell-cell adhesion. Changes in CDH1 function affect the epithelial-mesenchymal transition (EMT) that has been implicated as playing a role in tumorigenesis. Studies of affected HDGC individuals' tumors provide a unique opportunity to determine the essential drivers of diffuse gastric cancer in the context of $C D H 1$ loss of function. Supporting evidence of the role of $C D H 1$ in sporadic diffuse gastric cancers includes the observation that $50 \%$ contain $C D H 1$ mutations or hypermethylation of the $C D H 1$ promoter $[8,9]$. A recent whole genome sequencing survey of diffuse gastric cancer also identified frequent $C D H 1 \mathrm{mu}-$ tations as the most common driver event [4]. The TCGA gastric cancer data also show a high frequency of somatic CDH1 mutations [10]. Significantly less is known about the identity and role of co-occurring drivers that contribute to diffuse gastric metastasis.

Herein, we report a study of the metastatic evolutionary process in diffuse gastric cancer. Our goal was to identify known and candidate drivers that delineate the tumor progression during metastasis. We performed an extensive genome sequencing analysis of a primary gastric tumor and metastasis from an individual with a germline CDH1 mutation (Figure 1) who presented with a gastric primary, followed after 3 years by metastasis in the left ovary. Given the existing germline mutation in $C D H 1$, the cancer genome only requires a second allelic hit via a somatic genetic aberration, as is demonstrated in the tumor from this individual. Because the initial cancer driver event is known, Mendelian cancer genomes provide a rare and highly informative 'experiment of nature' that provides an opportunity to delineate somatic genetics of metastasis. Genome sequencing analysis of both tumors revealed evidence of a common origin based on shared mutations but greater genomic diversity seen both at the level of mutations as well as extensive allelic imbalance and copy number aberrations for the metatasis.

We determined if the candidate drivers from this metastatic progression were sufficient to reproduce diffuse gastric cancer. Our cancer modeling methodology used in vitro gastric organoids and allows one to engineer the genetic driver context of these cancers and study the process of metastatic evolution and oncogenic pathway divergence. Integrating genetic analysis and biological modeling, we determined the independent role of TGFBR2 (transforming growth factor- $\beta$ receptor 2) in the oncogenesis of diffuse gastric cancer. Our experimental cancer modeling relies on an air-liquid interface for primary mouse intestinal culture that contains both epithelial and mesenchymal elements, accurately recapitulates long-term proliferation, multilineage differentiation, the Wnt/Notch-dependent stem cell niche, and peristalsis [11]. We reported an analogous primary gastric organoid culture system that accurately recapitulates multilineage epithelial differentiation and stromal elements [12]. Recently, we achieved robust in vitro oncogenic transformation of primary gastric, colon, and pancreatic organoids via mutations in Kras and Trp53, which induce high-grade dysplasia and invasion in vitro with adenocarcinoma upon subcutaneous transplantation into mice [13]. We demonstrate the functional validation of candidate gastric cancer metastasis drivers

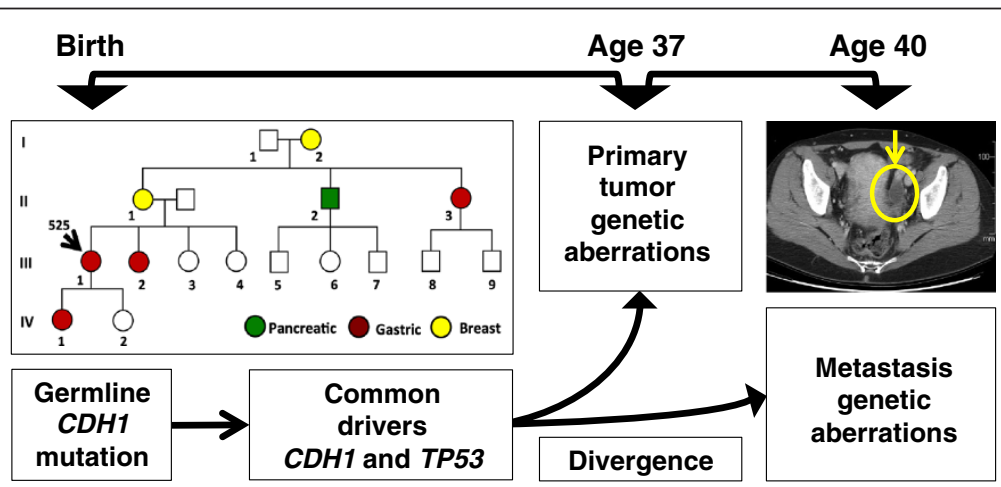

Figure 1 Family and clinical history of a Mendelian diffuse gastric cancer. The pedigree of the index patient 525 (III-1) is depicted. Tumor types are indicated by color including green for pancreatic cancer, red for diffuse gastric cancer, and yellow for breast cancer. The patient presented with her primary gastric cancer at the age of 37 years. Three years later she presented with an abdominal discomfort. Contrastenhanced CT scan of the pelvis identified a left ovary mass (yellow circle) that was confirmed on biopsy to be a diffuse gastric cancer metastasis (that is, Krukenberg tumor). During the course of metastatic tumor evolution, a number of known and candidate cancer driver events delineated the tumor evolution and genetic divergence of the metastasis from the primary tumor. 
from cancer genomic profiling studies, focusing on modeling the TGFBR2 driver as proof of principle.

\section{Results}

\section{Diffuse gastric cancer and metastatic progression}

At the age of 37 years, the index patient (525) was diagnosed with stage III (T3N1M0) poorly differentiated diffuse gastric adenocarcinoma (Figure 1). Her 42-year-old sister was diagnosed with diffuse gastric adenocarcinoma 2 months earlier. Based on the family history of gastric cancer and the unusually young age of onset, she underwent germline $C D H 1$ mutation testing. The patient and her sister were found to have a germline splice site mutation in intron 10 (c.1565 + 2insT). This germline mutation was subsequently reported in another family with hereditary diffuse gastric cancer (HDGC) [14]. The patient underwent a total gastrectomy to remove her primary tumor and was found to have a single lymph node metastasis. She received standard adjuvant treatment including combined chemotherapy (cisplatinum and 5-fluorouracil) and radiation. Three years after her initial presentation, the patient reported progressive lower abdominal fullness. A computed tomography (CT) scan demonstrated a large pelvic mass consistent with a left ovarian metastasis (Figure 1). Subsequently, the patient underwent laparotomy with bilateral salpingo-oophorectomy and biopsy of the pelvic mass. Pathological studies demonstrated metastatic adenocarcinoma involving the ovary, otherwise referred to as a Krukenberg tumor, with the same histologic appearance as the primary tumor. One study reported that among diffuse gastric cancer with metastatic dissemination, the ovary was a metastatic site in $28.8 \%$ of cases [15]. Thus, the ovary is a common site for metastatic disease.

\section{Cancer genome sequencing analysis}

Both exome and whole genome paired-end sequencing were performed on the primary tumor, ovarian metastasis, and normal tissue which included blood and normal gastric tissue (Additional file 1: Table S1). Tissue from the lymph node metastasis was not available for analysis. Multiple sequencing methods were employed to compensate for the extent of normal stromal mixture, a direct result of the infiltrative invasiveness of the diffuse gastric cancer subtype. We determined the extent of normal genome mixture and corrected for inclusion of the normal DNA (Additional file 1: Methods). Given the complexity of the tumor samples, we conducted an additional round of targeted sequencing to confirm the presence of mutations and other genetic aberrations that occurred in exons, near exon boundaries or promoters.

Overall, we obtained greater than $100 \times$ average coverage for each exome and generally relied on exome data for the discovery of coding region mutations. For whole genome sequencing, we had greater than $60 x$ average coverage for the primary cancer whole genome sample and $30 \times$ for the metastatic genome. The whole genome sequencing was used for identifying larger scale genetic aberrations such as copy number variation (CNVs), allelic imbalances, rearrangements, and other classes of structural rearrangements. After alignment, we conducted variant calling to identify somatic mutations and other classes of genetic aberrations. This included somatic mutations, insertion-deletions (indels), CNVs, loss-of-heterozygosity regions (LOH), and cancer rearrangements (Additional file 1: Table S3 and Table S4). As a control for single nucleotide variant calling, we genotyped the samples with Affymetrix 6.0 single nucleotide polymorphism (SNP) arrays; we compared the genotypes to the identified SNPS from the sequence data. The concordance of exome and whole genome SNP data to the array data was $99 \%$.

\section{Coding region mutations and validation with deep sequencing}

We identified mutations that occurred in exons and intronic mutations within 100 bases of the exon boundary and the results are summarized in Additional file 1: Table S2. As noted previously, the tumor samples had complex composition that reduced the sequence coverage of some mutations. We proceeded with an additional round of targeted sequencing to validate these mutations and determine their presence in both tumors. We designed an assay for deep targeted resequencing that covered approximately 300 bases around the specific mutation loci (Additional file 1: Table S5). The average targeted sequencing coverage for each putative mutation or loci was $278 \times$ for the normal, $251 \times$ for the primary tumor and $152 \times$ for the metastasis.

Between the two tumors, we independently validated a total of 77 mutations that occurred within or proximal to exons (Additional file 1: Methods and Table S5). Validated genetic aberrations included: (1) non-synonymous mutations, (2) synonymous mutations, (3) insertions, or (4) deletions. With the targeted sequencing data, we determined the mutation allelic frequency (MAF) between the primary tumor and metastasis for each mutation. This involves determining the fraction of a sequence read with a mutation in comparison to the reference sequence reads. We were able to identify which mutations were common or exclusive to the primary tumor versus the metastasis. Among the 77 validated mutations, the distribution was such that mutations were generally unique either to the primary tumor or metastatic site. For example, the primary tumor had eight mutations that were not present in the metastasis while the metastasis had 37 mutations not present in the primary tumor. Common to both cancers were 32 mutations. 
Given the interval of three years prior to the detection of the metastasis, there is a possibility that the metastasisspecific mutations occurred independently from the primary tumor. Mutations specific to the primary tumor that were not present in the ovarian metastasis may have been the result of random genetic drift. The mutations common to both indicate a common origin but the exact timing of the differentiation between the two tumors is less clear as noted by those mutations with lower MAF. A subset of these genes had high MAF values, indicating a higher likelihood of being present in all clonal populations in the primary tumor or metastasis. As we describe later, these genes were prioritized for further experimental testing in gastric organoids.

\section{Mutations affecting gene function}

Among the mutations that were externally validated, we focused on the subset of mutations leading to amino acid substitutions, premature stop codons and indels that altered the open reading frame. Subsequently, we determined if these coding mutations were potentially deleterious to gene function using a number of prediction algorithms such as Polyphen [16] and SIFT [17] among others. Based on the MAF information for each mutation, we determined whether these mutations with a possible deleterious impact on the gene products were common or exclusive to the primary tumor and metastasis (Figure 2).

On the subset of deleterious mutations, we conducted additional biological pathway analysis, literature review and comparison against the Cancer Genome Atlas data available for diffuse gastric cancer. This identified a set of known cancer genes and likely cancer-related candidates with mutations that likely had an impact on protein function. We focused on a number of candidate driver genes (Table 1) that had previously been demonstrated to have oncogenic potential or were known tumor suppressors with biallelic changes present in the cancer genomes.

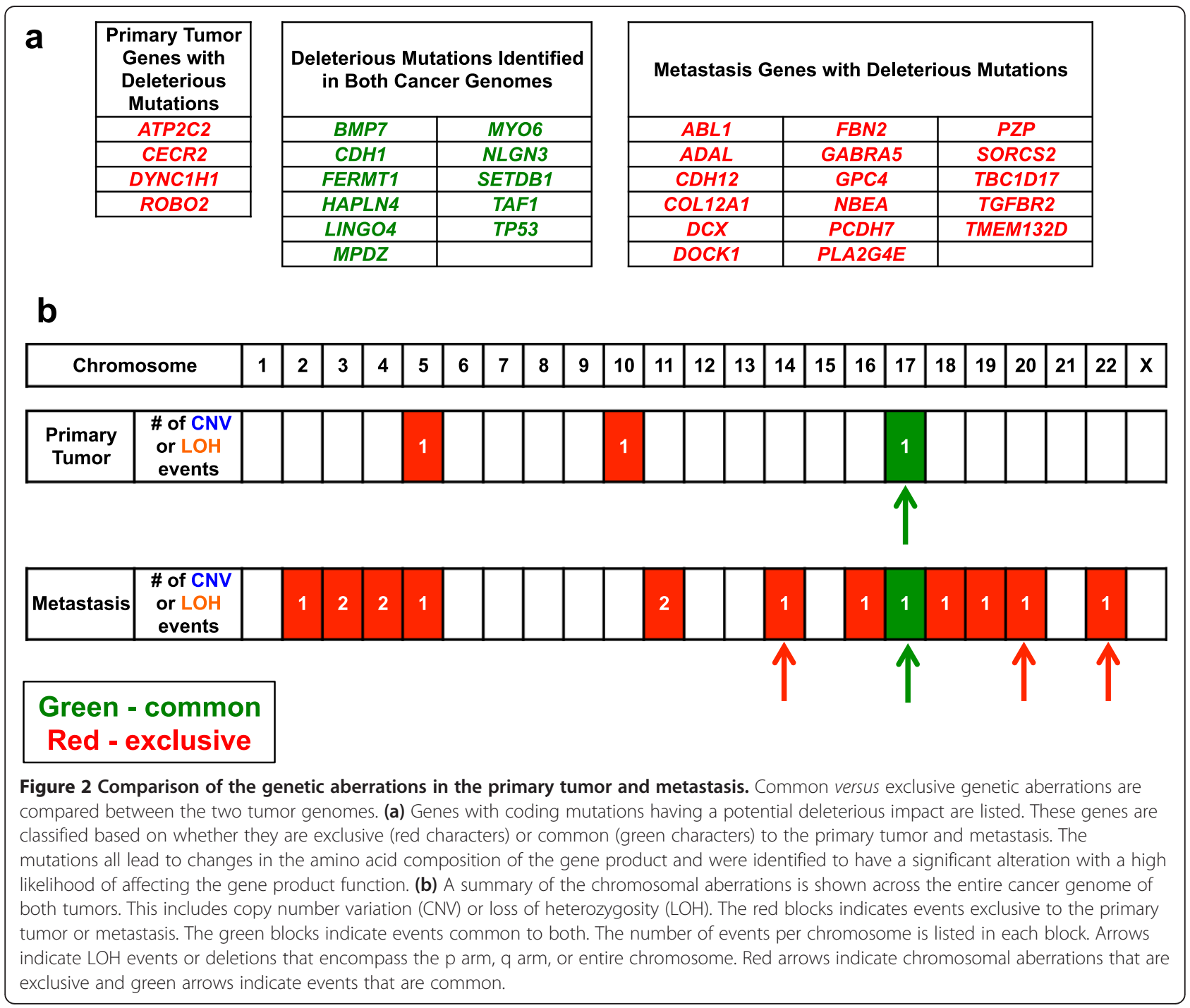


Table 1 Cancer oncogenes with amplifications or cancer drivers with biallelic events

\begin{tabular}{|c|c|c|c|c|c|c|c|}
\hline Origin & $\begin{array}{l}\text { Known or candidate } \\
\text { cancer driver }\end{array}$ & $\begin{array}{l}\text { Biallelic } \\
\text { event }\end{array}$ & $\begin{array}{l}\text { Allelic } \\
\text { alteration } 1\end{array}$ & $\begin{array}{l}\text { Mutation or genomic } \\
\text { aberration }\end{array}$ & Chr & Chr position or interval & Allelic alteration 2 \\
\hline Unique to the primary & FGFR2* & & Amplification & 6-fold amplification & 10 & $117820033-119748751$ & \\
\hline \multirow{2}{*}{$\begin{array}{l}\text { Common to the primary tumor and } \\
\text { metastasis }\end{array}$} & $\mathrm{CDH} 1$ & Yes & Deletion & Partial deletion of exon 9 & 16 & $68847326-68847403$ & Germline mutation in $\mathrm{CDH} 1$ \\
\hline & TP53 & Yes & $\begin{array}{l}5^{\prime} \text { splice site } \\
\text { mutation }\end{array}$ & Aberrant splicing & 17 & 7578370 & Hemizygous loss of $17 p$ arm \\
\hline \multirow[t]{4}{*}{ Unique to the metastasis } & TGFBR2 & Yes & Frameshift indel & Stop codon in exon 4 & 3 & 30691871 & $\begin{array}{l}\text { Hemizygous deletion of wild-type } \\
\text { TGFBR2 locus }\end{array}$ \\
\hline & $\mathrm{PCDH7}$ & Yes & Missense & S87R & 4 & 30723305 & $\begin{array}{l}\text { Hemizygous deletion of wild-type } \\
4 \mathrm{arm}\end{array}$ \\
\hline & FERMT1 loci & Yes & $\begin{array}{l}\text { Loss of } \\
\text { heterozygosity }\end{array}$ & FERMT1 located in 20p12.3 & 20 & & FERMT1 mutation \\
\hline & BMP7 loci & Yes & $\begin{array}{l}\text { Loss of } \\
\text { heterozygosity }\end{array}$ & BMP7 located in $20 q 13.3$ & 20 & & BMP7 mutation \\
\hline
\end{tabular}

Chr: chromosome. 
Copy number variations and allelic imbalances distinguishing the primary tumor from the metastasis

We noted larger scale genomic aberrations that differentiated the primary from the metastasis (Figures $2 \mathrm{~b}$ and $3 \mathrm{a}$ ). This included copy number changes and $\mathrm{LOH}$ events. Unique to the primary tumor were two genomic amplifications on chromosomes 5 and 10, and two inversions on chromosomes 15 and 16 (Additional file 1: Table S4). The chromosome 10 amplification covered a $1.66 \mathrm{Mb}$ interval. When considering deletions or allelic imbalances, the only major event that was noted involved a loss of the $\mathrm{p}$ arm of chromosome 17.

In contrast to the primary tumor, the metastatic tumor had numerous chromosomal scale LOH events and genomic deletions affecting 12 different chromosomes, the majority of which were unique to the metastatic tumor (Figure 2). This included multiple deletions and copy neutral LOH events that are detailed in Additional file 1: Table S3. There was a five-fold genomic amplification in chromosome 2 but no specific known genes existed in the affected interval. There were no detectable interchromosomal translocations in either the primary tumor or metastasis genomes. Other cancer rearrangements were identified but did not point towards aberrations in any candidate driver genes (Additional file 1: Table S4). There were indications of large scale genomic instability based upon allelic imbalance analysis; chromosomes 14, 17, 20, and 22 all involved the entire chromosome.

For copy number aberrations and allelic imbalances, we identified exclusive versus common events between the

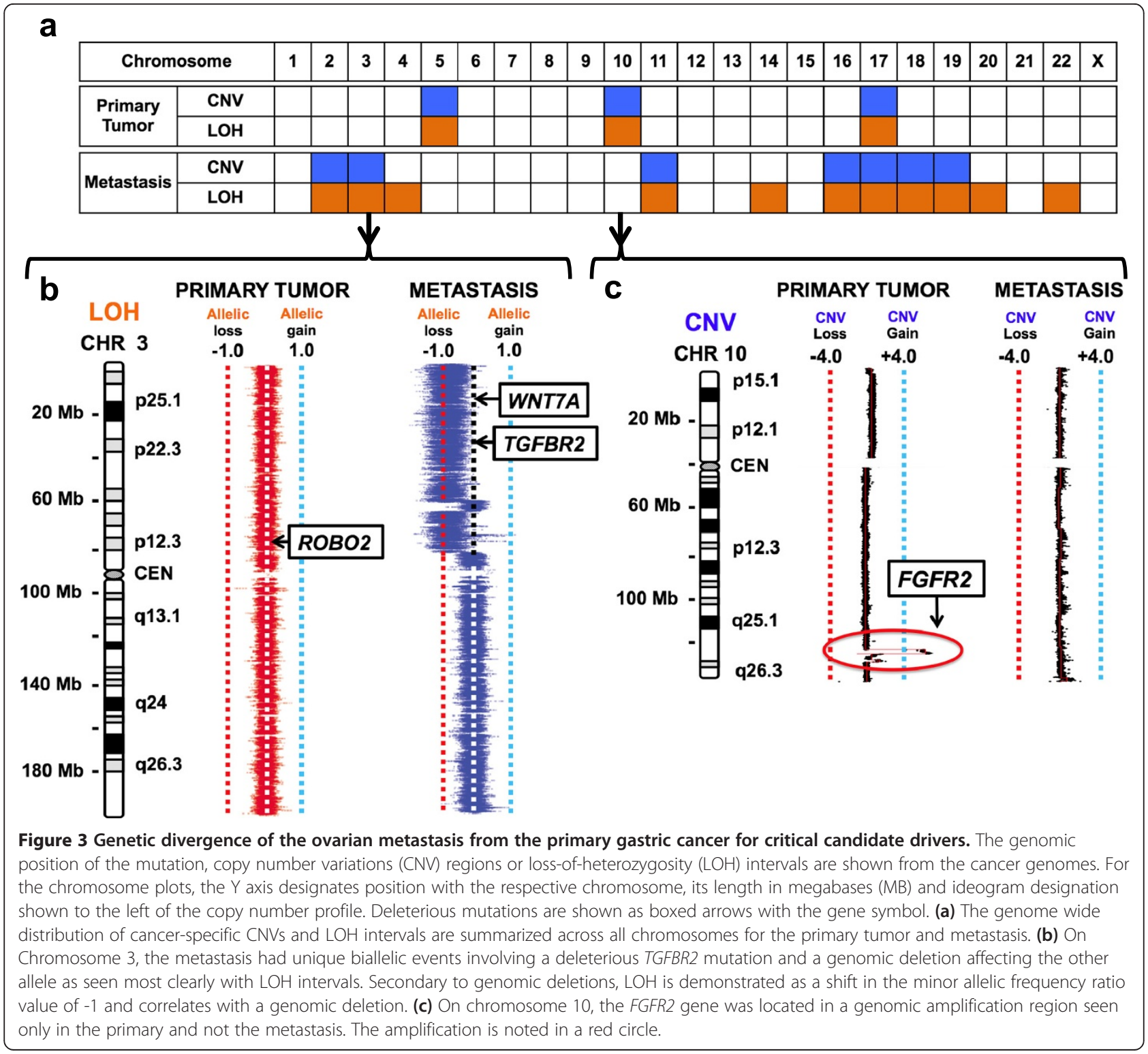


primary tumor and metastasis. The only common genetic aberration involved the $\mathrm{p}$ arm of chromosome 17. Overall, the lack of overlap was indicative of significant genetic divergence from the primary tumor and metastasis despite a common origin as denoted by shared mutations in critical tumor suppressors.

The genomic intervals of the $\mathrm{LOH}$, copy number aberration and rearrangement events were compared with the position of validated gene mutations. This integrated analysis pointed to a number of genes that had biallelic alterations involving both a loss of the wildtype allele from a large interval genomic aberration and a mutant allele. The results for genes with biallelic hits were considered to be strong candidates for a loss-offunction involvement in cancer (Table 1).

\section{Identification of cancer drivers common to the primary tumor and metastasis}

Both the primary and the metastasis contained cancer driver events that were likely to be critical for tumorigenesis in the context of the initial $C D H 1$ mutation (Table 1, Figure 2). In addition to the germline CDH1 intronic mutation, the second $C D H 1$ allele had a somatic $77 \mathrm{bp}$ genomic deletion of a portion of exon 9 that affects the downstream coding regions as well. The $C D H 1$ somatic mutation was identical in both the primary and metastatic gastric cancer genomes, demonstrating a common genetic origin and providing strong genetic evidence that this driver had a critical role in diffuse gastric tumorigenesis. Mutations affecting $C D H 1$ exon 9 that lead to loss of protein expression have frequently been detected in diffuse gastric cancer [18-20]. This exon's amino acid sequence is a putative calcium-binding site that is likely important for receptor function.

The primary and metastatic tumor also shared biallelic splice donor site mutation $(c .559+1 \mathrm{G}>\mathrm{A})$ of the fifth intron of TP53 and a chromosome 17p LOH event encompassing the TP53 locus (Additional file 1: Figure S1). The TP53 splicing mutation interrupts RNA splicing [21] and is a previously reported cancer mutation [22,23]. The analyses of sporadic and inherited gastric cancers have identified TP53 mutations that occur concurrently with $C D H 1$ mutation $[24,25]$. $C D H 1$ inactivation in gastric parietal cells does not induce gastric carcinoma, suggesting that loss of $C D H 1$ is insufficient for tumor initiation [26]. However, double conditional knockout of CDH1 and TP53 induces development of diffuse gastric carcinoma [26]. Interestingly, the genomic interval of the LOH event affecting the TP53 locus was larger in the metastasis compared to the primary tumor. This could have occurred because of independent genomic instability events given the strong selection for biallelic loss of TP53 function.

\section{FGFR2 is an actionable cancer driver exclusive to the primary gastric tumor}

In the primary tumor, there was a six-fold genomic amplification of a region of chromosome $10 \mathrm{q}$ arm and covered an interval of $1.66 \mathrm{Mb}$. Within this genomic regions was an oncogenic candidate driver FGFR2 also referred to as the fibroblast growth factor receptor 2 (Figure 3c). This was confirmed with multiple methods including sequencing, array analysis, and validation by quantitative PCR. FGFR2 is a transmembrane receptor that acts as part of a key signal transduction pathway regulating tissue repair and embryonic development among a host of other functions [26].

To validate the prevalence of FGFR2 amplification in diffuse versus intestinal gastric cancers, we analyzed 37 diffuse and 27 intestinal subtype primary gastric tumor samples with digital PCR [27]. Previously, we demonstrated that this method is profoundly sensitive for detecting copy number aberration even in the context of normal diploid DNA diluting tumor DNA. Our study demonstrated FGFR2 amplification in four of 37 (11\%) diffuse tumor samples, which was absent in the intestinal subtype samples (Figure 4a).

In support of its role as a candidate driver, FGFR2 amplification is present in a number of gastric cancer cell lines $[28,29]$ and subsequently reported in various gastrointestinal malignancies such as esophageal adenocarcinoma [30]. In addition, treatment of cancer cell lines with FGFR2-specific small molecule inhibitors or shRNAs leads to potent growth inhibition [28] suggesting a functional role for FGFR2 amplification in the diffuse subtype.

\section{Functional analysis of the FGFR2 driver in combination with $\mathrm{CDH} 1$ and TP53}

We identified two examples of a primary diffuse gastric cancer with co-occurrence of known and putative cancer drivers involving CDH1, TP53, and FGFR2 as seen in the index patient. The first example included a diffuse gastric cancer sample that was among the gastric adenocarcinomas analyzed by TCGA. Using the cBio TCGA portal [10], we identified a patient (TCGA-BR-6803) who had a similar complement of genetic aberrations in CDH1, TP53, and FGFR2, all of which have been previously described in cancer as seen in the COSMIC cancer mutation repository. This included the following: a missense mutation in CDH1 (D254Y) that has been described in three other cancers; a missense mutation (L130F) in TP53 where mutations in this codon have been reported in 37 other cancers; the FGFR2 amplification which we and others have identified in diffuse gastric cancer.

As the second example, we identified a human diffuse gastric cancer cell line, KatoIII, which has a similar composition of genetic aberrations affecting the same cancer 


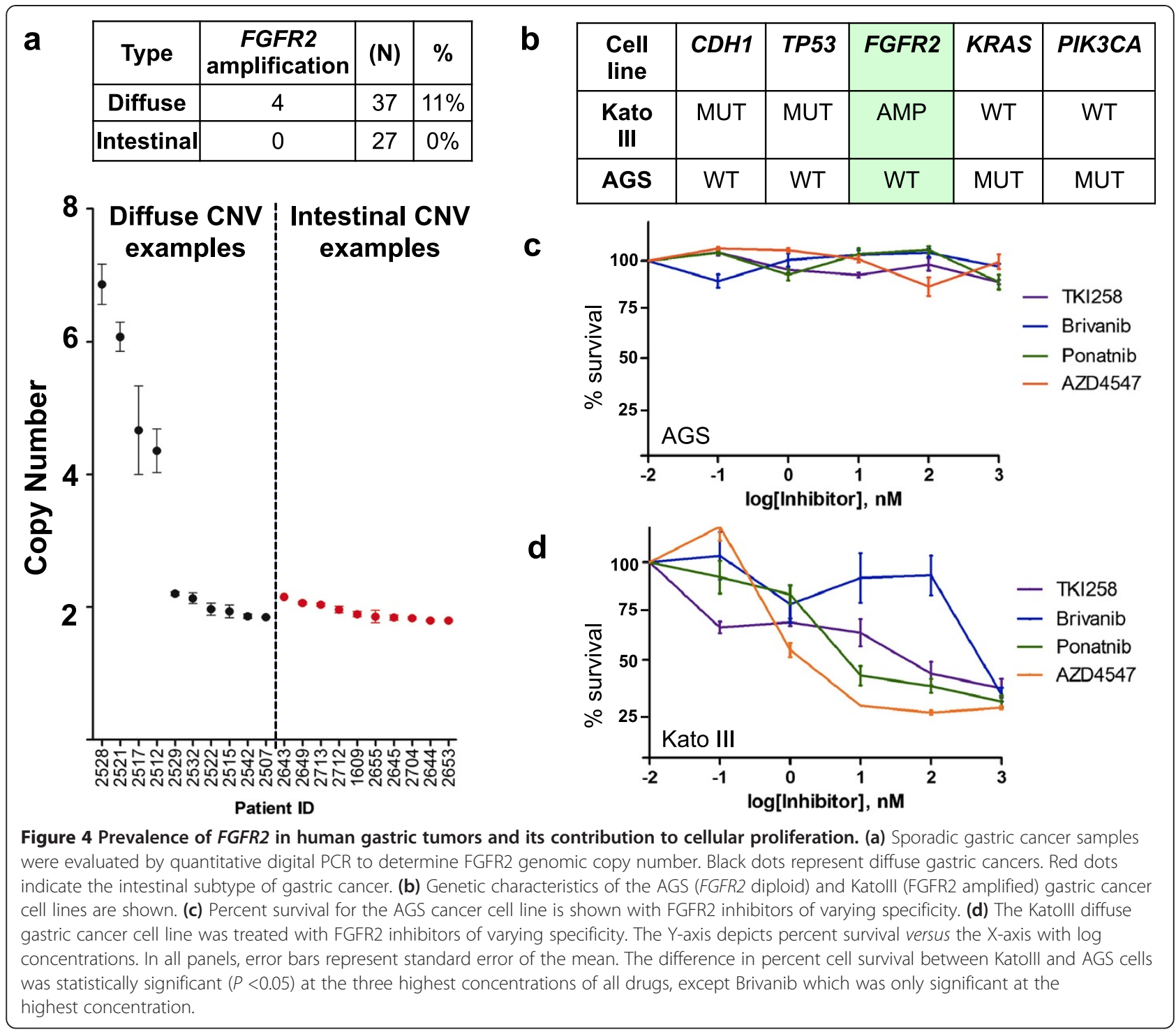

genes as the primary tumor of our index patient. KatolII has a $C D H 1$ mutation leading to an intronic sequence insertion in the mRNA [31,32], a TP53 mutation leading to a complete gene deletion [33] and the FGFR2 amplification [29] (Figure 4b). This cell line allowed us to assess the potential oncogenic role of the FGFR2 amplification in the specific genetic context of CDH1 and TP53 mutations, similar to the index patient's primary tumor.

To determine the contribution of FGFR signaling to neoplastic growth, we treated KatoIII cells with several FGFR2 small molecule tyrosine-kinase inhibitors (TKIs), including Brivanib, TKI258, Ponatinib, and AZD4547 [34]. As a control, we used the gastric cancer cell line AGS which is wild type for FGFR2, CDH1, and TP53, but has mutations in KRAS and PIK3CA [35] (Figure 4b). All FGFR2 inhibitors induced cell death in KatoIII but not AGS cells (Figure 4c and d). The most potent of these TKIs, AZD4547, has an $\mathrm{IC}_{50}$ of approximately $2 \mathrm{nM}$ in KatoIII cells and 39,580 nM in AGS cells (Figure 4c and d). Each of the inhibitors demonstrated a statistically significant lower $\mathrm{IC}_{50}$ in FGFR2amplified KatoIII cells compared to non-FGFR2-amplified AGS cells at all concentrations tested (Figure 4c and d).

In contrast, treatment of KatoIII and AGS cells with cytotoxic chemotherapeutic agents such as paclitaxel, 5fluorouracil and carboplatin did not have a significant effect on either KatoIII or AGS lines, with similar $\mathrm{IC}_{50}$ identified in each (Additional file 1: Table S7). For AZD4547, the 20,000-fold difference in sensitivity to FGFR inhibitors suggests that FGF signaling is a critical driver to $\mathrm{CDH1}$-initiated gastric cellular proliferation and this TKI represents a potential targeted therapy in diffuse subtype cancers harboring FGFR2 amplifications. 


\section{Biallelic inactivation of TGFBR2 is exclusive to the ovarian metastasis}

Genetic divergence was evident; the metastasis harbored its own unique subset of mutations and genomic aberrations. As we described, the metastasis had the same CDH1 and TP53 mutations as the primary tumor but lacked the FGFR2 amplification found in the primary cancer site (Figure 3c). To eliminate the possibility that the absence of FGFR2 amplification was related to a subpopulation not present in our original metastatic section, we performed a highly sensitive quantitative digital PCR on a separate geographic region from the metastasis (data not shown). This method has been previously been demonstrated to identify FGFR2 copy number amplifications with high sensitivity and specificity, even in the context of diluted mixtures [27]. This independent analysis again confirmed that the FGFR2 locus was not amplified in a separate region of the metastatic tumor.

The most striking event uniquely defining the metastasis was a TGFBR2 deletion in exon 3 (Table 1). We looked for the presence of this somatic mutation among the normal and primary tumor sequence from the independent datasets (for example, whole genome, exome, and deep targeted resequencing). The MAF of the mutation among all of these sequencing datasets indicated exclusivity specific to the ovarian metastasis (Additional file 1: Table S5). The mutation was not found in any significant fraction among the primary and normal genomes.

TGFBR2 encodes a receptor for the transforming growth factor $\beta$ (TGF- $\beta$ ) pathway. While TGFBR2 is mutated in numerous human cancers with particular prevalence in mismatch repair-deficient colon cancer [36], its functional relevance in gastric cancer is unknown. This particular deletion markedly reduces mRNA levels, presumably due to nonsense-mediated decay [37]. The metastasis also harbored a unique large genomic deletion of chromosome arm 3p encompassing the TGFBR2 locus as shown by both $\mathrm{CNV}$ and $\mathrm{LOH}$ events, resulting in biallelic events affecting the wildtype TGFBR2 alleles (Figure 3b).

TGFBR2 exon 3 deletions are typically associated with colorectal tumors displaying microsatellite instability (MSI), a molecular marker for the loss of DNA mismatch repair (MMR). We assessed the primary and metastatic tumor for DNA mismatch repair defects. The primary tumor had normal immunohistochemical staining for the major DNA mismatch repair proteins MLH1, MSH2, PMS2, and MSH6. Neither the primary tumor nor metastasis exhibited elevated MSI at any of the diagnostic genetic markers (Additional file 1: Table S7). In addition, the patient had no germline, primary tumor or metastatic somatic mutations in the MMR genes.

We examined the cBIO TCGA dataset for gastric cancers classified by the Lauren histopathologic criteria as diffuse. Among the TCGA set, three of 79 diffuse gastric tumor samples had mutations in TGFBR2. This included two cancers in which there was biallelic loss of the wildtype allele [10]. These samples were MSI stable. The diffuse subtype samples with TGFBR2 mutations include: a homozygous deletion (TCGA-BR-A4QM); biallelic mutations involving F442S and A426V in (TCGA-D7-6522); Q418 splice site mutation (TCGA-CD-8531). The examples of TGFBR2 mutations existing in diffuse gastric cancers are supportive evidence for the potential role of TGFBR2 as a driver.

\section{Other candidate cancer genes delineating the metastasis from the primary tumor}

Additional candidate cancer genes were identified that distinguished the metastasis from the primary gastric tumor (Table 1). A novel predicted pathogenic mutation in $B M P 7$ was identified in the primary and metastatic tumor but the metastatic tumor had a unique copy neutral loss of heterozygosity event encompassing the entire chromosome arm $20 \mathrm{q}$ including the BMP7 locus. BMP7 (that is, bone morphogenic protein) interacts with the TGF- $\beta$ pathway and has a well-studied role in osteoclast differentiation and bone development [38]. In addition, BMP7 expression has been correlated with tumor recurrence in gastric cancer [39].

Similarly, a novel DOCK1 mutation was uniquely identified in the metastatic genome. DOCK1 regulates cell motility and migration and has been implicated in ovarian cancer tumorigenesis [40] (Additional file 1: Table S5). Another genomic amplification unique to the primary tumor occurred in the $5 \mathrm{q} 22.3$ locus (Additional file 1: Table S3). Among the 15 genes within the amplification locus, the major oncogenic-related cancer gene was TRIM36 that is overexpressed in prostate cancer. It has been hypothesized its overexpression leads to chromosomal instability $[41,42]$.

\section{TGFBR2 knockdown in the context of CDH1 and TP53 is sufficient to induce metastatic diffuse gastric cancer in a primary gastric organoid murine model}

Given the metastasis-specific, biallelic alteration of TGFBR2, we exploited our validated primary air-liquid interface murine gastric organoid system [12,13] to investigate if TGFBR2 knockdown was sufficient to induce gastric cancer metastasis. Its consideration as a candidate was also suggested by the TCGA data. Previously, we observed that Trp53 deletion and $\operatorname{Kras}^{G 12 D}$ induced pronounced in vitro dysplasia and invasion of gastric organoids with in vivo tumorigenicity upon subcutaneous implantation, but spontaneous metastasis was not seen by 50 days [13].

Since both the primary and metastasis shared common CDH1 and TP53 mutations, primary gastric organoids 
were established from $C d h 1^{\mathrm{fl} / \mathrm{fl}} ; \operatorname{Trp} 53^{\mathrm{fl} / \mathrm{fl}}$ neonatal mouse stomach. Gastric organoid infection with a control adenovirus (Ad Fc) encoding an immunoglobulin Fc fragment [43] resulted in gastric organoids with wild-type Cdh1 and Tp53, while adenovirus Cre-green fluorescent protein (Ad Cre-GFP) induced deletion of the floxed Cdh1 and Trp53 alleles, with Cdh1 and Trp53 loss confirmed by immunofluorescence (Figure 5a and Additional file 1: Figure S2), accurately modeling the $C d h 1$ and $\operatorname{Trp} 53$ loss common to both the primary and metastatic tumors. As we previously reported [12,13], Ad Fc-treated organoids with wild-type Cdh1/Trp53 contained epithelial and mesenchymal components, accurately recapitulating in vivo stomach tissue architecture (Figure 5a and 5d).
To model the effect of the TGFBR2 in metastatic oncogenesis, we infected the same $C d h 1^{-1-} ; \operatorname{Tr} p 53^{-1-}$ gastric organoids with retrovirus expressing shRNA against $T g f b r 2$, confirming Tgfbr 2 knockdown by immunofluorescence and Western blot analysis (Figure 5a and b). Likewise, gene expression of Tgfbr2 was also reduced as determined by real time PCR (Additional file 1: Figure S3). The Tgfbr2 shRNA did not grossly increase the growth rate of $\mathrm{Cdh1}^{-1-} ; \operatorname{Trp}_{5} 3^{-/-}$gastric organoids over a 20-day period, possibly because of dominant effects of the Cdh1 and Trp53 deletions (Figure 5c). However, histologic analysis revealed that the resultant $\mathrm{Cdh1}^{-1-} ; \operatorname{Trp} 3^{-1-}$; Tgfbr2 shRNA gastric organoids but not $\mathrm{Cdh}^{1^{-1}}$; $\operatorname{Trp}_{5} 3^{-1-}$ controls demonstrated features of

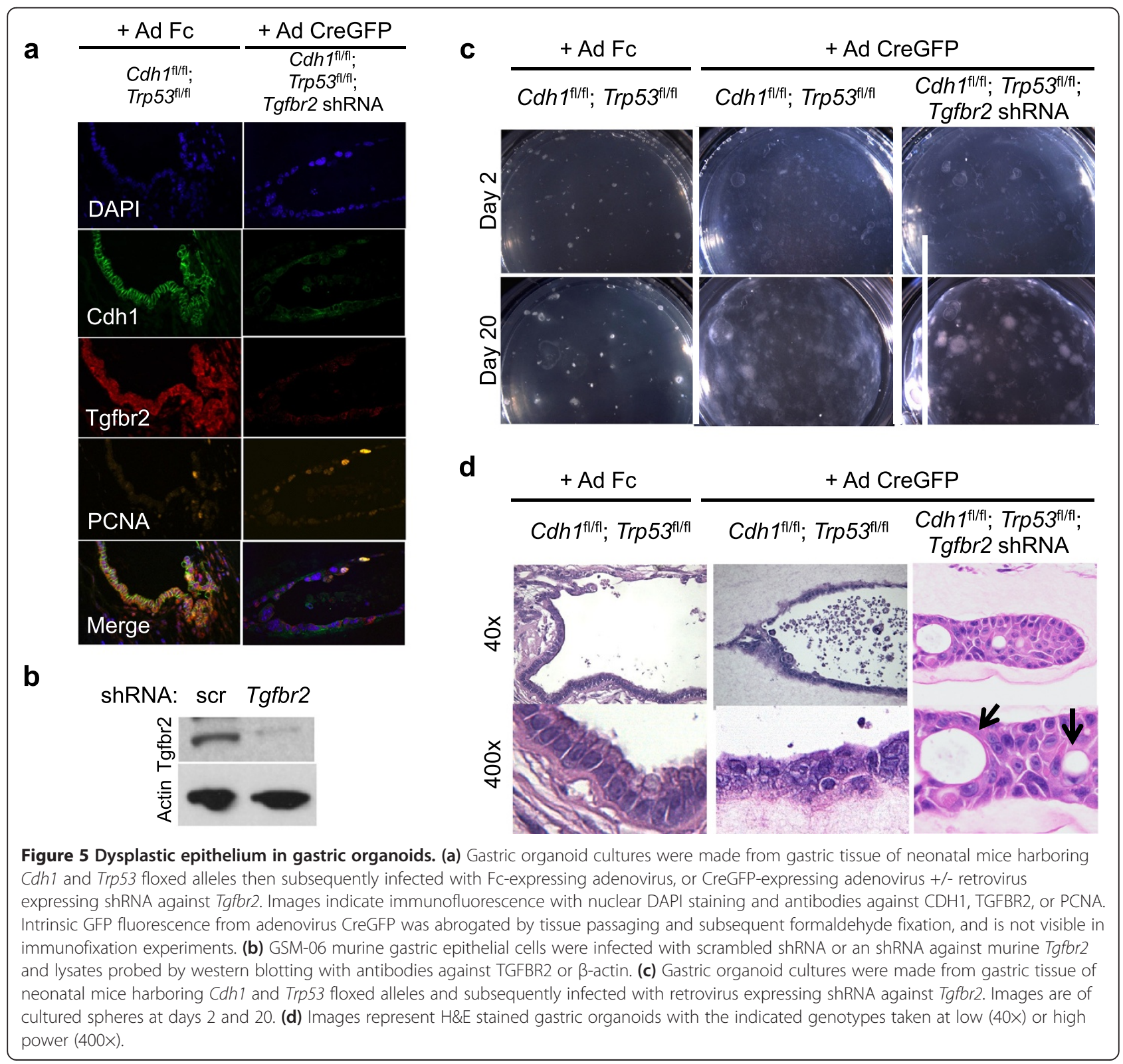


diffuse subtype gastric cancer. Severe dysplasia along with focal areas of invasion, signet ring formation, and nuclear pleomorphism were found throughout the analyzed organoids (Figure $5 \mathrm{~d}$ ).

To examine potential Tgfbr2 effects on in vivo metastasis, the $\mathrm{CdhH}^{-1-}$; Trp $53^{-1-} ; \mathrm{Tg} f b r 2$ shRNA organoids versus $\mathrm{Cdh1}^{-1} ; \mathrm{Trp} 53^{-1-}$ controls were disaggregated and injected subcutaneously into immunodeficient NOG mice. $C d h 1^{-1}$; $\operatorname{Trp} 53^{-/}$organoids produced extremely slow but detectable tumor growth by day 50 as we previously documented [13] (Figure 6a and b). In contrast, Cdh1 $1^{-1} ; \operatorname{Trp} 53^{-1}$;Tgfbr2 shRNA gastric organoids exhibited robust in vivo tumorigenicity (Figure 6a and c). Notably, Cdh1 $1^{-1-} ; \operatorname{Trp} 53^{-/-} ; \mathrm{Tg} f b r 2$ shRNA primary tumors exhibited a poorly differentiated adenocarcinoma histology with signet ring features as occurs in diffuse gastric cancer (Figure 6e to g). Immunofluorescence analysis confirmed loss of Cdh1 and Tgfbr2 knockdown (Figure 5a).

Evaluation for distant disease confirmed the presence of pulmonary metastases in NOG mice harboring Cdh1 $1^{-/} ; \operatorname{Trp} 53^{-/-} ; \operatorname{Tgfbr} 2$ shRNA tumors, comprised of poorly differentiated adenocarcinoma with signet ring features (Figure 6f, g). Metastatic tumors were located in the lungs bilaterally, were grossly observable upon dissection and had similar histologic appearance to diffuse gastric cancer. Overall, these studies support the role of $T g f b r 2$ as a putative tumor suppressor gene in diffuse gastric cancer, demonstrate successful in vitro conversion of primary gastric tissue to metastatic adenocarcinoma, and reveal the utility of a primary gastric organoid system for functional validation of candidate metastasis drivers.

\section{Discussion}

To address the question of identifying the genetic drivers of diffuse gastric cancer metastasis, we performed an extensive genome sequencing analysis of the metastatic evolutionary process. This involved sequencing of a matched gastric primary and subsequent metastasis from the same patient. We leveraged the unique Mendelian genetics of a HDCG proband as an 'experiment of nature' to delineate essential cancer drivers in diffuse gastric cancer.

Our genomic analysis revealed FGFR2 amplification exclusive to the primary gastric tumor and not present in the metastasis. Our results fully confirm several descriptions of FGFR2 amplification, as well as increased sensitivity of FGFR2-amplification positive cell lines such as KatoIII to small molecule FGFR inhibitors [44-47],

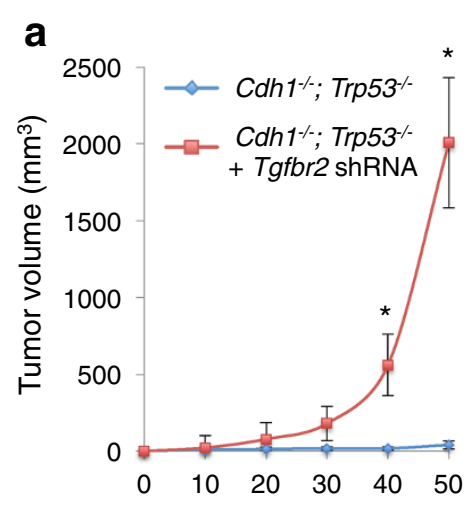

Days after transplantation

\section{s.c. primary tumor}

Cdh1 ${ }^{-}$; Trp53 $3^{-}+$Tgfbr2 shRNA

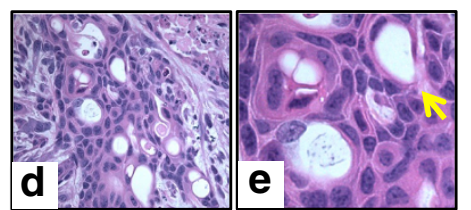

S.c. primary tumor

Cdh1\%; Trp53\%

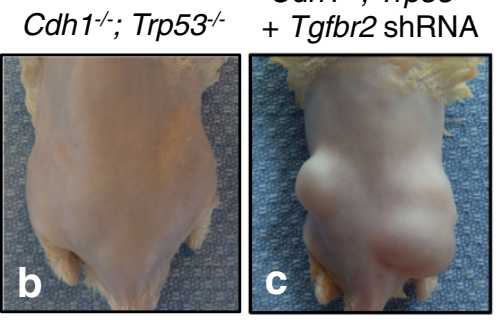

Spontaneous lung metastasis Cdh1 $\%$ Trp53\% + Tgfbr2 shRNA

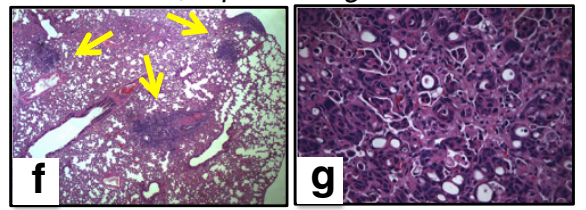

Figure 6 Gastric organoid tumor explants. Gastric organoids with the indicated genotypes are shown. (a) Tumor volumes were measured over time post-injection and plotted according to genotype of the driver combinations being tested. This includes $C d h 1^{--} ; \operatorname{Trp} 53^{-/-}$as shown in blue and

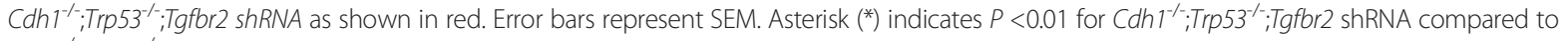
$\mathrm{Cdh}^{-1-} ; \mathrm{Trp}^{-1-}$ tumor volumes. (b, c) With different driver combinations, transformed gastric organoids were dissociated and subcutaneously (s.c.) injected into the flanks of immunodeficient NOG mice. Images indicated tumor growth at 30 days post injection. (d, e) Histological analysis of tumors confirms the presence of poorly differentiated adenocarcinoma with signet ring features, as indicated by the yellow arrows, only in the $\mathrm{Cdh} 1^{-1} ; \operatorname{Trp} 53^{-1}$; Tgfor2 shRNA organoids. After flank injections with dissociated organoids, histological analysis of murine lungs after 30 days revealed metastatic gastric adenocarcinoma with signet ring features at low (f) and high (g) magnification. 
with accompanying implications for FGFR2-targeted treatment [48]. The striking absence of FGFR2 amplification in the metastasis in the context of the common somatic CDH1 and TP53 mutations argues strongly for a tumor evolutionary divergence.

The functional validation of the metastatic potential of Tgfbr2 knockdown in our well-validated air-liquid interface gastric organoid method $[12,13]$ provides the first demonstration that TGFBR2 functions as a bona fide metastasis suppressor gene in diffuse gastric cancer. Homozygous TGFBR2 deletion is also present in a subset of TCGA gastric cancers [10] which are largely comprised of non-metastatic tumors. It will be interesting to evaluate whether TGFBR2 alterations are more prevalent in gastric metastases, such as to ovary or other sites. Furthermore, the functional relevance of other potential loci undergoing alteration in these samples merits additional exploration.

Our study also describes the first successful in vitro conversion of primary gastric tissue to metastatic gastric adenocarcinoma, suggesting the general applicability of the organoid method to the functional validation of gastric cancer loci involved in progression and/or metastasis. As shown here, such three-dimensional organoid-based functional validation strategies can potentially combine both the experimental tractability of two-dimensional culture of transformed cell lines with the accurate tissue ultrastructure and stromal components of transgenic mouse systems.

\section{Conclusions}

Exclusive FGFR2 and TGFBR2 genetic aberrations delineated the evolution of metastatic recurrence. Our finding may have implications for targeted cancer therapy. For example, the index patient in this study may have conceivably responded to a FGFR2 inhibitor based on FGFR2 amplification in the primary tumor. However, the patient's metastatic recurrence did not harbor this same FGFR2 amplification, suggesting that treatment with a therapeutic small molecule inhibitor may not have had a discernible biological effect on the patient's metastatic disease. In the precision management of individuals with metastatic cancer, one may need to account for the genetic heterogeneity and subsequent variation in cancer biology that differentiates metastatic sites from the primary tumor before the initiation of targeted therapy.

Although a comprehensive knowledge of the metastatic process is crucial for improved cancer treatment, the driver events underlying metastatic spread are unfortunately poorly understood [49]. Our paucity of knowledge regarding metastasis is further compounded by the relative omission of metastatic samples in large-scale genomic cancer surveys such as TCGA. This study is an initial effort to further address these questions about the genetics and biology of metastatic evolution by integrating genomic sequencing analysis with in vitro validation of clonal-specific candidate drivers.

\section{Materials and methods \\ Cancer samples}

This study was conducted in compliance with the Helsinki Declaration. The institutional review board (IRB) at Stanford University School of Medicine approved the study protocols (11886 and 19071). For all patients cited in this study, we obtained informed consent to conduct research and publish the results. Samples were obtained from the Stanford Cancer Institute Tissue Bank. Frozen tissue sections were prepared from each tumor and hematoxylineosin (H\&E) staining was performed on a single section. We estimated overall tumor composition that generally was approximately $50 \%$ or greater for most samples. Tumors were macro-dissected to increase tumor cellularity and processed for genomic DNA. Full details are in the Additional file 1: Methods.

\section{Sample preparation for whole genome, exome, and targeted resequencing analysis}

Genomic DNA was extracted from blood, normal gastric tissue and tumor samples using the E.Z.N.A. SQ DNA/ RNA Protein Kit (Omega Bio-Tek, Norcross, GA, USA). Concentrations of genomic DNA were determined with a Nanodrop instrument (Thermo Scientific, Wilmington, DE, USA). Genomic DNA from matched normal and cancer tissue were then used for creating sequencing libraries. DNA from peripheral leukoctyes was used for the Affymetrix SNP array.

From each sample, we fragmented $4 \mu \mathrm{g}$ of genomic DNA with a Covaris instrument (Covaris, Woburn, MA, USA). Illumina TruSeq Paired End libraries were constructed from double stranded, fragmented DNA per Illumina's standard protocol (Illumina, San Diego, CA, USA). The amplified material was recovered with a Qiaquick (Qiagen) column according to the manufacturer's instructions, except the DNA were eluted in $50 \mu \mathrm{L}$ water. The sequencing library DNA was quantified using the NanoDrop-1000 and the library was evaluated with an Agilent Bioanalyzer 2100 (Agilent, Santa Clara, CA, USA) using a DNA1000 chip. The mean library fragment size was found to be $300 \mathrm{bp}$ and these libraries were used for whole genome sequencing. For exome capture hybridization, we used Nimblegen SeqCap version 2 enrichment assay (Roche-Nimblegen, Madison, WI, USA). The methods were according to the NimbleGen's SeqCap EZ Exome Library SR User's Guide v2.2. Following the final amplification reaction, we purified the exome libraries using a Qiaquick column (Qiagen, Valencia, CA, USA) per the manufacturer's recommended protocol. 


\section{Cancer genome sequencing}

See Additional file 1 for complete details regarding the whole genome, exome, and targeted resequencing data analysis. This includes information about the targeted resequencing process, variant calling, allelic frequency determination, and mutation interpretation The oligonucleotide sequences for deep targeted resequencing are listed in Additional file 2.

\section{FGFR2 amplification analysis from diffuse and intestinal gastric cancers}

Quantitative PCR was performed using the Bio-Rad QX100 droplet digital PCR (ddPCR) system (Bio-Rad, Pleasanton, CA, USA). We used a standard set of FGFR2specific TaqMan primers and probes (Life Technology, Foster City, CA, USA) compared with standard references using an ultra-conserved region on chromosome 1 . Briefly, TaqMan PCR reaction mixtures were assembled using $2 \times$ ddPCR Supermix for probes, $20 \times$ assays $(18 \mu \mathrm{M}$ primers and $5 \mu \mathrm{M}$ probe) and restriction digested DNA samples (Biorad). To assess FGFR2 copy number, $125 \mathrm{ng}$ of each tumor DNA sample was digested with 1.25 units of BsaJI (NEB) in $15 \mu \mathrm{L}$ for $1 \mathrm{~h}$ at $60^{\circ} \mathrm{C}$. The digests were diluted 1.67 -fold to $25 \mu \mathrm{L}$ with nuclease free water then $25 \mathrm{ng}(5 \mu \mathrm{L})$ was assayed per $20 \mu \mathrm{L}$ ddPCR reaction. FGFR2 assay sequences were (forward primer) 5'-GGCT GGCTGCTGAAGTCT-3', (reverse primer) 5'-CTTAATC GCCTGTATGGTGGTAACA-3', and (probe) 5'-FAM-TC TTGGTCGTGTTCTTCATTCGGCACAG-BHQ1-3'. The FGFR2 assay was duplexed with a standard reference sequence on Chromosome 1. This standard reference assay used the following primers: (forward primer) 5'-TGAGG GATTCGGCAGATGTTG-3', (reverse primer) 5'-CTGAA AGGCTGGACTTGACAGA-3', and (probe) 5'-VIC-ACT GTGTGCTGGACCT-MGB-3'. All assay primers were ordered from Integrated DNA Technologies. Thermal cycling conditions were $95^{\circ} \mathrm{C} 10 \mathrm{~min}(1 \mathrm{cycle}), 94^{\circ} \mathrm{C} 30 \mathrm{~s}$ and $60^{\circ} \mathrm{C} 60 \mathrm{~s}$ (40 cycles), $98^{\circ} \mathrm{C} 10 \mathrm{~min}$ (1 cycle), and a $12^{\circ} \mathrm{C}$ hold. FGFR 2 copy number per cell was estimated as the ratio of the FGFR2 and RPP30 concentrations multiplied by two to account for the two copies of RPP30 that are expected per diploid genome. Analysis of the ddPCR data was performed using the CNV mode of the QX100 analysis software (version 1.2.9.0). Quadruplicate ddPCR wells were analyzed for each sample.

\section{FGFR2 inhibitor sensitivity assay}

KatoIII cells (HTB-103, ATCC) and AGS cells (CRL-1739, ATCC) were grown in Dulbecco's Modified Eagle Medium (DMEM), supplemented with 10\% fetal bovine serum and $100 \mathrm{U} / \mathrm{mL}$ of Pen Strep Glutamine (Gibco). All cells were cultured at $37^{\circ} \mathrm{C}$ in a humidified atmosphere and $5 \%$ $\mathrm{CO}_{2}$. Survival of KatoIII and AGS cells was determined using the WST-1 Proliferation Assay (Roche). We tested multiple FGFR inhibitors including TKI-258, Brivanib (BMS-540215), Ponatnib (AP24534), and AZD4547 (Selleck Chemical). Cells were seeded at a density of $2 \times 10^{4}$ cells/well in 96-well microtiter plates, $100 \mu \mathrm{L}$ medium/well and maintained $18 \mathrm{~h}$ for attachment. Afterwards, we treated the cultures with varying concentrations of each drug diluted in DMSO. After $30 \mathrm{~h}$ incubation, $10 \mu \mathrm{L}$ of WST-1 reagent was added followed by $1 \mathrm{~h}$ at $37^{\circ} \mathrm{C}$. The cleavage of tetrazolium salt (WST-1) into a visible formazan by viable cells was spectrophotometrically measured using a reference wavelength of $450 \mathrm{~nm}$. Each test was performed in triplicate. Percentages of cell survival were calculated as follows:\% cell survival $=$ (absorbance of treated cells/ absorbance of cells with vehicle solvent $) \times 100$. The half inhibitory concentration $\left(\mathrm{IC}_{50}\right)$ was calculated with a non-linear regression from the dose-response curve.

\section{Mismatch repair protein immunohistochemistry}

Mismatch repair protein immunohistochemistry was performed on the primary diffuse gastric tumor using the standard streptavidin-biotin-peroxidase procedure. Primary monoclonal antibodies against MLH1 (clone G168-728, 1:200, BD PharMingen, San Diego, CA, USA 1:200), MSH2 (clone FE11, 1:100, Oncogene Research Products, Cambridge, MA, USA), MSH6 (clone 44, 1:200, BD Transduction, San Jose, CA, USA) and PMS2 (clone MRQ-28, 1:10, Cell Marque, Rocklin, CA, USA) were applied to formalin-fixed, paraffin embedded sections four microns thick. The sections were deparaffinized in xylene, and rehydrated through graded alcohols to distilled water before undergoing antigen retrieval by heat treatment in either citrate solution pH 6.0 (MLH1, PMS2, and MSH2) or EDTA solution pH 9.0 (MSH6). An automated detection using a Leica Bond Autostainer (Leica, Buffalo Groove, IL, USA) was employed. Normal expression was defined as nuclear staining within tumor cells, using infiltrating lymphocytes as positive internal control. Negative protein expression was defined as complete absence of nuclear staining within tumor cells in the face of concurrent positive labeling in internal non-neoplastic tissues.

\section{Gastric organoid cancer modeling in mice and functional analysis}

All procedure involving animal were approved the Stanford University Administrative Panel on Laboratory Animal Care and was fully compliant with the USDA Animal Welfare Act, and our Assurance of Compliance with the PHS Policy on Human Care and Use of Laboratory Animals. Air-liquid interface organoid culture was performed as described [11,12].

$C d h 1^{\text {flox/flox }} ; \operatorname{Tr} p 53^{\text {flox/flox }}$ mice were generated by crossing $C d h 1^{\text {flox/flox }}$ mice, obtained from Jackson Laboratory, and $\operatorname{Trp} 53^{\text {flox/flox }}$ mice, kindly provided by Dr. Anton Berns [50] NOD.Cg-Prkdc ${ }^{\text {scid }}$ Il2rg ${ }^{\text {tm1Sug/JicTac }}$ 
mice were obtained from Taconic Farms, Inc. We dissected stomachs from neonatal mice (age P1-10) and washed them in cold PBS to remove all luminal contents. We extensively minced either large $25 \%$ sections or any entire neonatal stomach per dish and embedded the minced tissues in a 3D collagen gel using a doubledish air-liquid interface culture system as previously described [11]. To maintain the organoids, we applied fresh medium (F12, 20\%FCS, gentamicin $50 \mathrm{ug} / \mathrm{mL}$ ) every week.

Tgfbr2 shRNAs were obtained from Origene (catalog TG516186). Retroviral plasmids were cotransfected with pCL-Eco into $293 \mathrm{~T}$ cells by Lipofectamine2000 (Invitrogen). Retroviral supernatants were collected 48 and $72 \mathrm{~h}$ post-transfection and concentrated by PEG-it virus precipitation solution ( $5 \times$, System Biosciences). Virus titer was determined by infection of NIH3T3 cells and FACS analysis of GFP positive cells $48 \mathrm{~h}$ post infection. $C d h 1^{\text {flox/flox }} ; \operatorname{Trp} 53^{\text {flox/flox }}$ gastric organoids were infected at day 0 with adenovirus Ad Cre-GFP (University of Iowa Vector Core) or control adenovirus Ad Fc [43] encoding a mouse immunoglobulin IgG2 $\alpha$ Fc fragment by layering viral particles $\left(10^{9} \mathrm{pfu}\right)$ suspended in $500 \mu \mathrm{L}$ culture media over the top of the collagen matrix containing primary tissue. For retrovirus infection of secondary organoids, primary organoids at 14 to 20 days of growth were recovered from collagen gel by collagenase IV (Worthington) incubation followed by $0.05 \%$ trypsin/ EDTA incubation to dissociate organoids into a single cell suspension. Following extensive washing with $10 \%$ FBS to inactivate collagenase/trypsin, cells were pelleted by centrifugation and incubated with retroviral particles ( $2 \mu \mathrm{L}$ of $10^{8} \mathrm{pfu} / \mathrm{mL}$ ) encoding Tgfbr2-shRNA in the presence of growth medium and TransDux (System Biosciences) at room temperature for $60 \mathrm{~min}$ before serial replating into 3D collagen gel air-liquid interface culture.

Samples were fixed with $4 \%$ paraformaldehyde overnight, paraffin-embedded, sectioned, and sections stained by H\&E for initial histology analysis. Further immunohistochemistry analysis, used the following antibodies: PCNA (1:300; Invitrogen), CDH1 (1:300; BD Biosciences Pharmagen), TGFBR2 (1:250; Abbiotec), p53 (1:100; Santa Cruz). Cell lysates of mouse gastric culture cell or GSM-06 cells transfected with $T g f b r 2$-shRNA-GFP were immunoblotted with TGFBR2 (1:2,000, Abbiotec) and $\beta$-actin (1:2,000, Abcam).

Cells from gastric organoids were collected from the air-liquid interface collagen gel by disaggregation with collagenase IV (Worthington). For transplantation, 400,000 cells per mouse flank were mixed with matrigel (50\% Matrigel, $10 \% \mathrm{FCS}, 40 \% \mathrm{~F} 12,100 \mu \mathrm{L}$ of Matrigel mixture per $=$ mouse) and injected into NOD.CgPrkdc ${ }^{\text {scid }}$ Ilr2rg ${ }^{\text {tm1Sug/JicTac }}$ mice. Mice were sacrificed after day 50 , after which tumors were dissected and examined by $H \& E$ staining. $P$ values were determined using a two-tailed Student's t-test assuming unequal variances. A $P$ value of 0.05 was considered significant.

\section{Data availability}

The data from this study have been submitted to the NCBI Sequence Read Archive under the accession number SRP044347.

\section{Additional files}

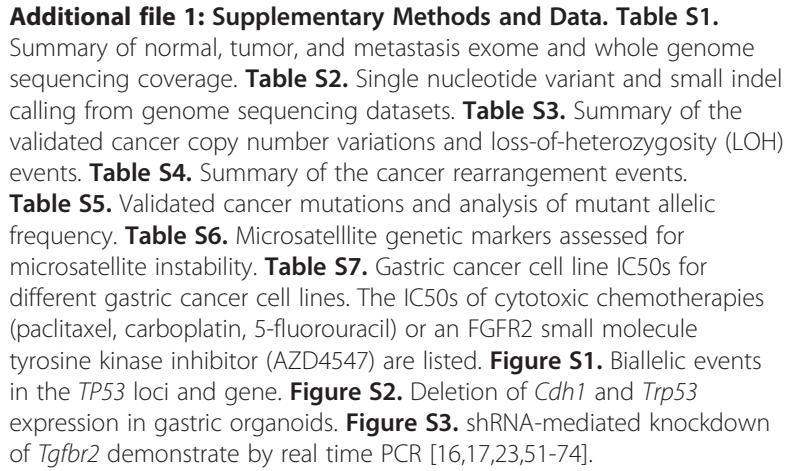

Additional file 2: Table S8. Mutation targeted sequencing study.

\section{Abbreviations}

Ad: Adenovirus; BMP: Bone morphogenic protein; CNV: Copy number variation; ddPCR: Droplet digital PCR; EMT: Epithelial mesenchymal transition; FGFR2: Fibroblast growth factor receptor 2; GFP: Green fluorescent protein; H\&E: Hematoxylin-eosin; HDGC: Hereditary diffuse gastric cancer;

indel: Insertion-deletions; IRB: Institutional review board; LOH: Loss of heterozygosity; MAF: Minor allele frequency; Mb: Megabase; SNP: Single nucleotide polymorphism; TCGA: The Cancer Genome Atlas; TGFBR2: Transforming growth factor- $\beta$ receptor 2 ; TKl: tyrosine kinase inhibitor.

\section{Competing interests}

Dr. John Regan is an employee of Bio-Rad that manufactures the droplet digital PCR system used in this study.

\section{Authors' contributions}

HPJ, LDN, and JMF designed the analysis of the HDGC patient. HX and ESH conducted the sequencing assays. LDN, LM, and JR conducted molecular assays for validation. SG, GN, JMB, PF, CP, HC, NRZ, and HPJ conducted the sequencing data and genetic analysis. RKP provided pathologic review of the gastric cancers and organoids. LDN and LM conducted the cell line and organoid experiments. LDN, AO, and CJK developed the organoid system. CJK supervised the development of cancer organoid modeling. HPJ supervised and coordinated all aspects of the analysis and experiments. All authors revised, read, and approved the final manuscript.

\section{Acknowledgements}

HPJ was supported by a Research Scholar Grant, RSG-13-297-01-TBG, from the American Cancer Society. HPJ received additional support from the Doris Duke Clinical Foundation Clinical Scientist Development Award and a Howard Hughes Medical Institute Early Career Grant. Other support came from the Gastric Cancer Foundation (HPJ, JMF). We also acknowledge support from National Institutes of Health Grants Digestive Disease Center DK56339 (HPJ, LN), P01 HG000205 (EH, JMB, SG, PF, and HPJ), NHGRI RC2 HG005570 (GN, JMB, HX, and HPJ), NCI Innovative Molecular Analysis Technology 1R33CA1745701 (JMB and HPJ), NHGRI R01 HG006137 (HPJ and NZ), NCl Tumor Microenvironment Network Consortium 1U01CA151920 (CJK and HPJ), NCI Cancer Target and Discovery Consortium U01CA17629901 (CJK and HPJ), NIDDK and NIAID Intestinal Stem Cell Consortium 1U01DK085527 (CJK) and K08 CA166512 (LN). LN received additional support from an American Society for Clinical Oncology Young Investigator Award. 


\section{Author details}

'Division of Oncology, Department of Medicine, Stanford University School of Medicine, CCSR 1115, 269 Campus Drive, Stanford, CA 94305-5151, USA. ${ }^{2}$ Stanford Genome Technology Center, Stanford University, Palo Alto, CA 94304, USA. ${ }^{3}$ Department of Pathology, University of Pittsburgh Medical Center, Pittsburgh, PA 15213, USA. ${ }^{4}$ Bio-Rad, Inc, Pleasanton, CA 94566, USA. ${ }^{5}$ Department of Statistics, Stanford University, Stanford, CA 94305, USA. ${ }^{6}$ Division of Hematology, Department of Medicine, Stanford University School of Medicine, CCSR 1155, 269 Campus Drive, Stanford, CA 94305-5151, USA. ${ }^{7}$ Department of Statistics, The Wharton School, University of Pennsylvania, Philadelphia, PA 19104, USA.

Received: 29 April 2014 Accepted: 27 August 2014

Published: 27 August 2014

\section{References}

1. Lauren P: Histogenesis of intestinal and diffuse types of gastric carcinoma. Scand J Gastroentero/ Supp/ 1991, 180:160-164.

2. Cunningham D, Allum WH, Stenning SP, Thompson JN, Van de Velde CJ Nicolson M, Scarffe JH, Lofts FJ, Falk SJ, Iveson TJ, Smith DB, Langley RE, Verma M, Weeden S, Chua YJ, MAGIC Trial Participants: Perioperative chemotherapy versus surgery alone for resectable gastroesophageal cancer. N Engl J Med 2006, 355:11-20.

3. Lim L, Michael M, Mann GB, Leong T: Adjuvant therapy in gastric cancer. J Clin Oncol 2005, 23:6220-6232.

4. Lee YS, Cho YS, Lee GK, Lee S, Kim YW, Jho S, Kim HM, Hong SH, Hwang JA, Kim SY, Hong D, Choi IJ, Kim BC, Kim BC, Kim CH, Choi H, Kim Y, Kim KW, Kong G, Kim HL, Bhak J, Lee SH, Lee JS: Genomic profile analysis of diffuse-type gastric cancers. Genome Biol 2014, 15:R55.

5. Yamashita K, Sakuramoto S, Watanabe M: Genomic and epigenetic profiles of gastric cancer: potential diagnostic and therapeutic applications. Surg Today 2011, 41:24-38.

6. Cisco RM, Ford JM, Norton JA: Hereditary diffuse gastric cancer: implications of genetic testing for screening and prophylactic surgery. Cancer 2008, 113:1850-1856.

7. Chen Y, Kingham K, Ford JM, Rosing J, Van Dam J, Jeffrey RB, Longacre TA, Chun N, Kurian A, Norton JA: A prospective study of total gastrectomy for CDH1-positive hereditary diffuse gastric cancer. Ann Surg Oncol 2011, 18:2594-2598.

8. Becker KF, Atkinson MJ, Reich U, Becker I, Nekarda H, Siewert JR, Hofler H: E-cadherin gene mutations provide clues to diffuse type gastric carcinomas. Cancer Res 1994, 54:3845-3852.

9. Machado JC, Oliveira C, Carvalho R, Soares P, Berx G, Caldas C, Seruca R, Carneiro F, Sobrinho-Simoes M: E-cadherin gene $(\mathrm{CDH} 1)$ promoter methylation as the second hit in sporadic diffuse gastric carcinoma. Oncogene 2001, 20:1525-1528.

10. Cerami E, Gao J, Dogrusoz U, Gross BE, Sumer SO, Aksoy BA, Jacobsen A Byrne CJ, Heuer ML, Larsson E, Antipin Y, Reva B, Goldberg AP, Sander C, Schultz N: The cBio cancer genomics portal: an open platform for exploring multidimensional cancer genomics data. Cancer Discov 2012, 2:401-404

11. Ootani A, Li X, Sangiorgi E, Ho QT, Ueno H, Toda S, Sugihara H, Fujimoto K, Weissman IL, Capecchi MR, Kuo CJ: Sustained in vitro intestinal epithelial culture within a Wnt-dependent stem cell niche. Nat Med 2009, 15:701-706.

12. Katano T, Ootani A, Mizoshita T, Tanida S, Tsukamoto H, Ozeki K, Ebi M, Mori Y, Kataoka H, Kamiya T, Toda S, Joh T: Establishment of a long-term threedimensional primary culture of mouse glandular stomach epithelial cells within the stem cell niche. Biochem Biophys Res Commun 2013 432:558-563.

13. Li X, Nadauld L, Ootani A, Corney DC, Pai RK, Gevaert O, Cantrell MA, Rack PG, Neal JT, Chan CW, Yeung T, Gong X, Yuan J, Wilhelmy J, Robine S, Attardi LD, Plevritis SK, Hung KE, Chen CZ, Ji HP, Kuo JC: Oncogenic transformation of diverse gastrointestinal tissues in primary organoid culture. Nat Med 2014, 20:769-777.

14. Kluijt I, Siemerink EJ, Ausems MG, van Os TA, de Jong D, Simoes-Correia J, van Krieken JH, Ligtenberg MJ, Figueiredo J, van Riel E, Sijmons RH, Plukker JT, van Hillegersberg $\mathrm{R}$, Dekker E, Oliveira C, Cats A, Hoogerbrugge N, Dutch Working Group on Hereditary Gastric Cancer: $\mathrm{CDH} 1$-related hereditary diffuse gastric cancer syndrome: Clinical variations and implications for counseling. Int J Cancer 2012, 131:367-376.
15. Hass HG, Smith $U$, Jager $C$, Schaffer M, Wellhausser $U$, Hehr T, Markmann $\mathrm{HU}$, Nehls O, Denzlinger C: Signet ring cell carcinoma of the stomach is significantly associated with poor prognosis and diffuse gastric cancer (Lauren's): single-center experience of 160 cases. Onkologie 2011, 34:682-686

16. Adzhubei IA, Schmidt S, Peshkin L, Ramensky VE, Gerasimova A, Bork P, Kondrashov AS, Sunyaev SR: A method and server for predicting damaging missense mutations. Nat Methods 2010, 7:248-249.

17. Kumar P, Henikoff S, Ng PC: Predicting the effects of coding nonsynonymous variants on protein function using the SIFT algorithm. Nat Protoc 2009, 4:1073-1081.

18. Berx G, Becker KF, Hofler H, van Roy F: Mutations of the human E-cadherin (CDH1) gene. Hum Mutat 1998, 12:226-237.

19. Gamboa-Dominguez A, Dominguez-Fonseca C, Chavarri-Guerra $Y$, Vargas R, Reyes-Gutierrez E, Green D, Quintanilla-Martinez L, Luber B, Busch R, Becker KF, Becker I, Hofler H, Fend F: E-cadherin expression in sporadic gastric cancer from Mexico: exon 8 and 9 deletions are infrequent events associated with poor survival. Hum Pathol 2005, 36:29-35

20. Hiraguri S, Godfrey T, Nakamura H, Graff J, Collins C, Shayesteh L, Doggett N, Johnson K, Wheelock M, Herman J, Baylin S, Pinkel D, Gray J: Mechanisms of inactivation of E-cadherin in breast cancer cell lines. Cancer Res 1998, 58:1972-1977.

21. Foti A, Bar-Eli M, Ahuja HG, Cline MJ: A splicing mutation account for the lack of p53 gene expression in a CML blast crisis cell line: a novel mechanism of p53 gene inactivation. Br J Haematol 1990, 76:143-145.

22. Petitjean A, Achatz MI, Borresen-Dale AL, Hainaut P, Olivier M: TP53 mutations in human cancers: functional selection and impact on cancer prognosis and outcomes. Oncogene 2007, 26:2157-2165.

23. Forbes SA, Bindal N, Bamford S, Cole C, Kok CY, Beare D, Jia M, Shepherd R, Leung K, Menzies A, Teague JW, Campbell PJ, Stratton MR, Futreal PA: COSMIC: mining complete cancer genomes in the Catalogue of Somatic Mutations in Cancer. Nucleic Acids Res 2011, 39:D945-D950.

24. Strickler JG, Zheng J, Shu Q, Burgart LJ, Alberts SR, Shibata D: p53 mutations and microsatellite instability in sporadic gastric cancer: when guardians fail. Cancer Res 1994, 54:4750-4755.

25. Tamura G, Sakata K, Nishizuka S, Maesawa C, Suzuki Y, Iwaya T, Terashima M, Saito K, Satodate R: Inactivation of the E-cadherin gene in primary gastric carcinomas and gastric carcinoma cell lines. Jpn J Cancer Res 1996, 87:1153-1159.

26. Shimada S, Mimata A, Sekine M, Mogushi K, Akiyama Y, Fukamachi $H$, Jonkers J, Tanaka H, Eishi Y, Yuasa Y: Synergistic tumour suppressor activity of E-cadherin and p53 in a conditional mouse model for metastatic diffuse-type gastric cancer. Gut 2012, 61:344-353.

27. Nadauld LD, Regan JF, Miotke L, Pai RK, Longacre TA, Kwok SS, Saxonov S, Ford JM, Ji HP: Quantitative and sensitive detection of cancer genome amplifications from formalin fixed paraffin embedded tumors with droplet digital PCR. Transl Med (Sunnyvale) 2012, 2:1-5.

28. Kunii K, Davis L, Gorenstein J, Hatch H, Yashiro M, Di Bacco A, Elbi C, Lutterbach B: FGFR2-amplified gastric cancer cell lines require FGFR2 and Erbb3 signaling for growth and survival. Cancer Res 2008, 68:2340-2348.

29. Tsujimoto H, Sugihara $H$, Hagiwara A, Hattori T: Amplification of growth factor receptor genes and DNA ploidy pattern in the progression of gastric cancer. Virchows Arch 1997, 431:383-389.

30. Dulak AM, Schumacher SE, van Lieshout J, Imamura Y, Fox C, Shim B, Ramos AH, Saksena G, Baca SC, Baselga J, Tabernero J, Barretina J, Enzinger PC, Corso G, Roviello F, Lin L, Bandla S, Luketich JD, Pennathur A, Meyerson M Ogino S, Shivdasani RA, Beer DG, Godfrey TE, Beroukhim R, Bass AJ: Gastrointestinal adenocarcinomas of the esophagus, stomach, and colon exhibit distinct patterns of genome instability and oncogenesis Cancer Res 2012, 72:4383-4393.

31. Bass AJ, Lawrence MS, Brace LE, Ramos AH, Drier Y, Cibulskis K, Sougnez C, Voet D, Saksena G, Sivachenko A, Jing R, Parkin M, Pugh T, Verhakk RG, Stransky N, Boutin AT, Barretina J, Solit DB, Vakiani E, Shao W, Mishina Y, Warmuth M, Jimenez J, Chiang DY, Signoretti S, Kaelin WG, Spardy N, Hahn WC, Hoshida Y, Ogino S, et al: Genomic sequencing of colorectal adenocarcinomas identifies a recurrent VTI1A-TCF7L2 fusion. Nat Genet 2011, 43:964-968. 
32. Oda T, Kanai $Y$, Oyama T, Yoshiura K, Shimoyama $Y$, Birchmeier W, Sugimura $T$, Hirohashi S: E-cadherin gene mutations in human gastric carcinoma cell lines. Proc Natl Acad Sci U S A 1994, 91:1858-1862.

33. Yamada Y, Yoshida T, Hayashi K, Sekiya T, Yokota J, Hirohashi S, Nakatani K, Nakano $H$, Sugimura T, Terada M: p53 gene mutations in gastric cancer metastases and in gastric cancer cell lines derived from metastases. Cancer Res 1991, 51:5800-5805.

34. Gavine PR, Mooney L, Kilgour E, Thomas AP, Al-Kadhimi K, Beck S, Rooney C, Coleman T, Baker D, Mellor MJ, Brooks AN, Klinowska T: AZD4547: an orally bioavailable, potent, and selective inhibitor of the fibroblast growth factor receptor tyrosine kinase family. Cancer Res 2012, 72:2045-2056.

35. Yoon YK, Kim HP, Han SW, Hur HS, Oh do Y, Im SA, Bang YJ, Kim TY: Combination of EGFR and MEK1/2 inhibitor shows synergistic effects by suppressing EGFR/HER3-dependent AKT activation in human gastric cancer cells. Mol Cancer Ther 2009, 8:2526-2536.

36. Bellam N, Pasche B: Tgf-beta signaling alterations and colon cancer. Cancer Treat Res 2010, 155:85-103.

37. Markowitz S, Wang J, Myeroff L, Parsons R, Sun L, Lutterbaugh J, Fan RS, Zborowska E, Kinzler KW, Vogelstein B: Inactivation of the type II TGF-beta receptor in colon cancer cells with microsatellite instability. Science 1995, 268:1336-1338.

38. Itoh F, Asao H, Sugamura K, Heldin CH, ten Dijke P, Itoh S: Promoting bone morphogenetic protein signaling through negative regulation of inhibitory Smads. EMBO J 2001, 20:4132-4142.

39. Aoki M, Ishigami S, Uenosono $Y$, Arigami T, Uchikado $Y$, Kita Y, Kurahara H, Matsumoto M, Ueno S, Natsugoe S: Expression of BMP-7 in human gastric cancer and its clinical significance. Br J Cancer 2011, 104:714-718.

40. Wang $H$, Linghu $H$, Wang J, Che YL, Xiang TX, Tang WX, Yao ZW: The role of Crk/Dock180/Rac1 pathway in the malignant behavior of human ovarian cancer cell SKOV3. Tumour Biol 2010, 31:59-67.

41. Balint I, Muller A, Nagy A, Kovacs G: Cloning and characterisation of the RBCC728/TRIM36 zinc-binding protein from the tumor suppressor gene region at chromosome 5q22.3. Gene 2004, 332:45-50.

42. Miyajima N, Maruyama S, Nonomura K, Hatakeyama S: TRIM36 interacts with the kinetochore protein CENP-H and delays cell cycle progression. Biochem Biophys Res Commun 2009, 381:383-387.

43. Wei K, Piecewicz SM, McGinnis LM, Taniguchi CM, Wiegand SJ, Anderson K, Chan CW, Mulligan KX, Kuo D, Yuan J, Vallon M, Morton L, Lefai E, Simon MC, Maher JJ, Mithieux G, Rajas F, Annes J, McGuinness OP, Thurston G, Giaccia AJ, Kuo CJ: A liver Hif-2alpha-Irs2 pathway sensitizes hepatic insulin signaling and is modulated by Vegf inhibition. Nat Med 2013, 19:1331-1337.

44. Nakatani H, Sakamoto H, Yoshida T, Yokota J, Tahara E, Sugimura T, Terada M: Isolation of an amplified DNA sequence in stomach cancer. Jpn $J$ Cancer Res 1990, 81:707-710.

45. Su X, Zhan P, Gavine PR, Morgan S, Womack C, Ni X, Shen D, Bang YJ, Im SA, Ho Kim W, Jung E-J, Grabsch HI, Kilgour E: FGFR2 amplification has prognostic significance in gastric cancer: results from a large international multicentre study. Br J Cancer 2014, 110:967-975.

46. Xie L, Su X, Zhang L, Yin X, Tang L, Zhang X, Xu Y, Gao Z, Liu K, Zhou M, Gao B, Shen D, Zhang L, Ji J, Gavine PR, Zhang J, Kilgour E, Zhang X, Ji Q: FGFR2 gene amplification in gastric cancer predicts sensitivity to the selective FGFR inhibitor AZD4547. Clin Cancer Res 2013, 19:2572-2583

47. Lee J, Ou SH: Towards the goal of personalized medicine in gastric cancer-time to move beyond HER2 inhibition. Part I: Targeting receptor tyrosine kinase gene amplification. Discov Med 2013, 15:333-341.

48. Roychowdhury S, lyer MK, Robinson DR, Lonigro RJ, Wu YM, Cao X, KalyanaSundaram S, Sam L, Balbin OA, Quist MJ, Barrette T, Everett J, Siddiqui J, Kunju LP, Navone N, Araujo JC, Troncoso P, Logothetis CJ, Innis JW, Smith DC, Lao CD, Kim SY, Roberts JS, Gruber SB, Pienta KJ, Talpaz M, Chinnaiyan AM: Personalized oncology through integrative high-throughput sequencing: a pilot study. Sci Transl Med 2011, 3:111ra121.

49. Nguyen DX, Massague J: Genetic determinants of cancer metastasis. Nat Rev Genet 2007, 8:341-352.

50. Meuwissen R, Linn SC, Linnoila Rl, Zevenhoven J, Mooi WJ, Berns A: Induction of small cell lung cancer by somatic inactivation of both Trp53 and Rb1 in a conditional mouse model. Cancer Cell 2003, 4:181-189.

51. Fitzgerald RC, Hardwick R, Huntsman D, Carneiro F, Guilford P, Blair V, Chung DC, Norton J, Ragunath K, Van Krieken JH, Dwerryhouse S, Caldas C, International Gastric Cancer Linkage Consortium: Hereditary diffuse gastric cancer: updated consensus guidelines for clinical management and directions for future research. J Med Genet 2010, 47:436-444

52. Igartua C, Turner EH, Ng SB, Hodges E, Hannon GJ, Bhattacharjee A, Rieder MJ, Nickerson DA, Shendure J: Targeted enrichment of specific regions in the human genome by array hybridization. Curr Protoc Hum Genet 2010, Chapter 18:Unit 1813

53. Li H, Durbin R: Fast and accurate long-read alignment with Burrows-Wheeler transform. Bioinformatics 2010, 26:589-595.

54. McKenna A, Hanna M, Banks E, Sivachenko A, Cibulskis K, Kernytsky A, Garimella K, Altshuler D, Gabriel S, Daly M, DePristo MA: The Genome Analysis Toolkit: a MapReduce framework for analyzing next-generation DNA sequencing data. Genome Res 2010, 20:1297-1303.

55. Koboldt DC, Chen K, Wylie T, Larson DE, McLellan MD, Mardis ER, Weinstock GM, Wilson RK, Ding L: VarScan: variant detection in massively parallel sequencing of individual and pooled samples. Bioinformatics 2009, 25:2283-2285

56. DePristo MA, Banks E, Poplin R, Garimella KV, Maguire JR, Hartl C, Philippakis AA, del Angel G, Rivas MA, Hanna M, McKenna A, Fennell TJ, Kernytsky AM, Sivachenko AY, Cibulskis K, Gabriel SB, Altshuler D, Daly MJ: A framework for variation discovery and genotyping using next-generation DNA sequencing data. Nat Genet 2011, 43:491-498.

57. Bhagwat M: Searching NCBI's dbSNP database. Curr Protoc Bioinformatics 2010, Chapter 1:Unit 119.

58. Sherry ST, Ward MH, Kholodov M, Baker J, Phan L, Smigielski EM, Sirotkin K: dbSNP: the NCBI database of genetic variation. Nucleic Acids Res 2001, 29:308-311.

59. A map of human genome variation from population-scale sequencing. Nature 2010, 467:1061-1073.

60. Solomon E, Voss R, Hall V, Bodmer WF, Jass JR, Jeffreys AJ, Lucibello FC, Patel I, Rider $\mathrm{SH}$ : Chromosome 5 allele loss in human colorectal carcinomas. Nature 1987, 328:616-619.

61. Bettegowda C, Agrawal N, Jiao Y, Sausen M, Wood LD, Hruban RH, Rodriguez FJ, Cahill DP, McLendon R, Riggins G, Velculescu VE, Oba-Shinjo SM, Marie SK, Vogelstein B, Bigner D, Yan H, Papadopoulos N, Kinzler KW: Mutations in CIC and FUBP1 contribute to human oligodendroglioma. Science 2011, 333:1453-1455.

62. Chen $H$, Xing $H$, Zhang NR: Estimation of parent specific DNA copy number in tumors using high-density genotyping arrays. PLoS Comput Biol 2011, 7:e1001060.

63. Shen JJ, Zhang NR: Change-point model on non-homogeneous Poisson processes with application in copy number profiling by next-generation DNA sequencing. Ann App/ Stat 2012, 6:476-496.

64. Chen K, Wallis JW, McLellan MD, Larson DE, Kalicki JM, Pohl CS, McGrath SD, Wendl MC, Zhang Q, Locke DP, Shi X, Fulton RS, Ley TJ, Wilson RK, Ding L, Mardis ER: BreakDancer: an algorithm for high-resolution mapping of genomic structural variation. Nat Methods 2009, 6:677-681.

65. Lam HY, Pan C, Clark MJ, Lacroute P, Chen R, Haraksingh R, O'Huallachain M, Gerstein MB, Kidd JM, Bustamante CD, Snyder M: Detecting and annotating genetic variations using the HugeSeq pipeline. Nat Biotechnol 2012, 30:226-229.

66. Ye K, Schulz MH, Long Q, Apweiler R, Ning Z: Pindel: a pattern growth approach to detect break points of large deletions and medium sized insertions from pairedend short reads. Bioinformatics 2009, 25:2865-2871.

67. Abyzov A, Urban AE, Snyder M, Gerstein M: CNVnator: an approach to discover, genotype, and characterize typical and atypical CNVs from family and population genome sequencing. Genome Res 2011, 21:974-984.

68. Lam HY, Mu XJ, Stutz AM, Tanzer A, Cayting PD, Snyder M, Kim PM, Korbel JO, Gerstein MB: Nucleotide-resolution analysis of structural variants using BreakSeq and a breakpoint library. Nat Biotechnol 2010, 28:47-55.

69. Myllykangas S, Buenrostro JD, Natsoulis G, Ji HP, Bell JM: Efficient targeted resequencing of human germline and cancer genomes by oligonucleotideselective sequencing. Nat Biotechnol 2011, 29:1024-1027.

70. Robinson JT, Thorvaldsdottir H, Winckler W, Guttman M, Lander ES, Getz G, Mesirov JP: Integrative genomics viewer. Nat Biotechnol 2011, 29:24-26.

71. Zerbino DR, Birney E: Velvet: algorithms for de novo short read assembly using de Bruijn graphs. Genome Res 2008, 18:821-829.

72. Reimand J, Kull M, Peterson H, Hansen J: Vilo J: g:Profiler-a web-based toolset for functional profiling of gene lists from large-scale experiments. Nucleic Acids Res 2007, 35:W193-W200.

73. Kanehisa M, Goto S, Sato Y, Furumichi M, Tanabe M: KEGG for integration and interpretation of large-scale molecular data sets. Nucleic Acids Res 2012, 40:D109-D114. 
74. Ding L, Ley TJ, Larson DE, Miller CA, Koboldt DC, Welch JS, Ritchey JK, Young MA, Lamprecht T, McLellan MD, McMichael JF, Wallis JW, Lu C, Shen D, Harris CC, Dooling DJ, Fulton RS, Fulton LL, Chen K, Schmidt H, Kalicki-Veizer J, Magrini VJ, Cook L, McGrath SD, Vickery TL, Wendl MC, Heath S, Watson MA, Link DC, Tomasson MH, et al: Clonal evolution in relapsed acute myeloid leukaemia revealed by whole-genome sequencing. Nature 2012, 481:506-510.

doi:10.1186/s13059-014-0428-9

Cite this article as: Nadauld et al.: Metastatic tumor evolution and organoid modeling implicate TGFBR2 as a cancer driver in diffuse gastric cancer. Genome Biology 2014 15:428.

\section{Submit your next manuscript to BioMed Central} and take full advantage of:

- Convenient online submission

- Thorough peer review

- No space constraints or color figure charges

- Immediate publication on acceptance

- Inclusion in PubMed, CAS, Scopus and Google Scholar

- Research which is freely available for redistribution 